\title{
The Global Significance Of Locus Of Control In Ethical Decision Making: A Multi-Country Examination Of University Students
}

Aileen Smith, (Email: asmith@sfasu.edu), Stephen F. Austin State University Evelyn C. Hume, (Email: humeec@mail.longwood.edu), Longwood University Ray Zimmermann, (Email: rzimmer@utep.edu), University of Texas, El Paso Alan Davis, Truman State University

\begin{abstract}
Locus of control (LOC) is a personality variable shown to possess potential explanatory power in the study of ethical decision making. There have been, however, diverse results reported in the literature. Whenever differences on this variable are indicated by the research, individuals with an Internal LOC report the more ethical responses. This study extends the examination of the global relevance of the LOC variable to ethical decision making of university students in thirteen universities from eight countries. Using an instrument designed to elicit responses to questionable academic behaviors, this research analyzes ethical responses of university students $(n=2,420)$ to look for differences based on the LOC variable. The behaviors examined are of a collaborative or collectivistic nature, and the students were asked to respond to how unethical they believe the academic behaviors to be. Results indicate considerable support for the global significance of LOC differences in the ethical responses of the students.
\end{abstract}

\section{INTRODUCTION}

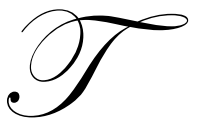

he ethics spotlight focused on corporate actions continues to glow as stakeholders demand ever greater accountability from CEOs, CFOs and managers. Scandals involving major companies such as Enron, WorldCom, Adelphia, Tyco, and others have raised awareness of the need for ethics education. As colleges and universities prepare the global business leaders of tomorrow, it is important to understand the factors and characteristics that influence individuals' ethicality and their decisions when faced with ethical dilemmas. Moreover, in the international arena in which most corporations now operate and in which educational institutions now function, understanding systemic differences in ethical decision making is vital to preparing business students to deal with the complex ethical decisions they will face during their careers.

Some research has shown locus of control (LOC) to be a significant factor in ethical decision making among individuals in certain cultural groups. When faced with an ethical dilemma, generally individuals with an internal LOC respond more ethically than do those with an external LOC. In order to further examine the ethical decision processes of our future business leaders, this study examines links between responses to ethical dilemmas and the LOC orientation of the university student respondents across eight cultural groups.

\section{LITERATURE REVIEW}

The examination of the ethical orientation of university students in the US has been reported in the literature for several decades. During the last few years, additional studies have examined ethical decision making of students in 
the international academic domain. Using a country variable in the analysis, research comparing North American students to those from Western European countries or Australia generally has not indicated significant differences in the ethical beliefs and perceptions of students among these countries (Eynon et al., 1996; Stevenson and Bodkin, 1998; Whipple and Swords, 1992; Lysonski and Gaidis, 1991). Given the predominance of the common Anglo-Saxon heritage, these results are not unexpected. An increasing number of cross-national studies have compared Angloheritage countries with various Asian subgroups. In general, the differences in the responses on the ethical survey items of these geographically and culturally diverse groups are significantly different (Armstrong, 1996; Brody et al., 1998; Goodwin and Goodwin, 1999; Nyaw and Ng, 1994; White and Rhodeback, 1992). However, some research examining cultural differences of Anglo and Asian university students indicate considerable correspondence associated with the responses between the geographical regions. The differences appear to be in the use of the survey responses provided by the Likert scale (Yamamura et al., 1996; Ueno and Wu, 1993). Asian students tend to prefer the more collectivistic mid-points of the scale and ignore the more individualistic end-points of scales provided with surveys.

A number of studies have addressed the potential link between the personality variable Locus of Control (LOC) and ethical responses. Rotter's (1966) LOC instrument is designed to assess how much control an individual believes he/she has over the outcomes in life. LOC is based on whether an individual believes there is a causal relationship between his/her decisions and behaviors and the potential outcomes of those decisions and behaviors. An Internal person believes in a causal link between his/her decisions or actions and the expected consequences. Internals believe that the consequences of their lives are directly related to the decisions they make and the actions they take. In general Internals accept responsibility for what happens to them because they believe the consequences are linked to their decisions. Externals believe that the expected outcomes or consequences in their lives are not linked to their own efforts or decisions. Instead, they believe the outcomes are under the control of luck, fate, or powerful others. Externals do not generally believe in the acceptance of responsibility of what happens to them because their belief structure does not include a cause-and-effect relationship between the precedent behavior and the subsequent consequence.

Research studies have offered some support for the Internal/External LOC distinction in the ethical research using university students. As expected, some research results indicate support for the belief that Internals will supply the more ethical responses to the surveys and scenarios considered (Hagerty and Sims, 1978; Brownell, 1981; Jones and Kavanaugh, 1996; McCuddy and Peery, 1996; Terpstra et al., 1991; Ameen et al., 1996; Trevino \& Youngblood, 1990; Smith et al., 1998/99; Smith et al., 2004). Other studies have found only limited support for the LOC variable effect in ethical research using university students (Hagerty and Sims, 1979; Rogers and Smith, 2001). Some research has also reported no ethical response differences on the LOC variable (Brownell, 1982; Geurin and Kohut, 1989; Bass et al., 1999; Jones \& Kavanaugh, 1996).

Additional research has examined the importance of LOC in a personal and environmental control context. A number of studies have found general support for the Internal's preference for a participative decision style and expression of greater work satisfaction (Brownell, 1982, 1981; Geurin and Kohut, 1989; Licata et al., 1986; Spector and Michaels, 1986; Storms and Spector, 1987). These results additionally support the position that Internals expect a cause-and-effect relationship between their actions and the resulting outcomes of those actions and would prefer to actively participate in the decision making process.

\section{RESEARCH HYPOTHESIS}

This research extends the examination of LOC differences in ethical responses of university students. Specifically, it examines whether there is evidence of LOC differences in multi-country data. Because Internals believe in the linking of their attitudes and actions with the subsequent outcomes of those actions, it is expected that the Internal/External LOC distinction will have explanatory effect in the students' responses.

$\mathrm{H}$ : Internal LOC respondents are expected to report more ethically sensitive responses on collaborative survey items than External LOC respondents. 


\section{METHODOLOGY}

Data $(n=2,420)$ for the analysis were collected from university students from the US and seven other countries. Demographic information on the student respondents is shown in Table 1.

\begin{tabular}{|l|l|l|l|}
\hline \multicolumn{3}{|c|}{ Table 1 - Respondent Demographics } \\
\hline Gender: & $\underline{\mathrm{n}^{*}}$ & $\underline{\text { Age: }}$ & $\underline{\mathrm{n}}^{*}$ \\
Male & 1,087 & $\leq 20$ Years & 1,034 \\
Female & $\underline{1,320}$ & $21-25$ years & 252 \\
Total & 2,407 & $>35$ years & $\underline{76}$ \\
\hline Locus of Control: & $\underline{\mathrm{n}}$ & Total & \\
Internal $(\leq 10)$ & 1,338 & & \\
External $(\geq 11)$ & $\underline{1,082}$ & & \\
Total & 2,420 & & \\
\hline Not all totals equal 2,420 due to response omissions.
\end{tabular}

Because the data were collected from intact classroom situations, there was $100 \%$ participation. The students completed the surveys during class time and were assured individual anonymity. Table 2 shows the countries/jurisdictions represented by the data.

\begin{tabular}{|l|c|c|c|}
\hline \multicolumn{4}{|c|}{ Table 2 - Countries/Jurisdictions Represented in the Data } \\
\hline & $\underline{\mathrm{n}}$ & & $\underline{\mathrm{n}}$ \\
China & 176 & Hong Kong & 319 \\
Columbia & 20 & Puerto Rico & 64 \\
Finland & 84 & USA & 1,601 \\
Germany & 52 & Viet Nam & $\underline{104}$ \\
& & Total & 2,420 \\
\hline
\end{tabular}

Most scholars would agree that research is needed to examine real-world business situations. However, often university students do not have the requisite knowledge or experience to be able to respond appropriately to survey questions reflecting real-world business dilemmas. The ethically questionable items surveyed by the current research were selected because they sampled behaviors that were considered to be familiar to the students' academic environment. The survey requested that the subjects respond to their beliefs concerning questionable behaviors in an academic environment. The actions included are also generally considered to be collaborative or collectivistic behaviors.

The questionnaire contained three parts. The first part requested from the students information regarding the students' own personal beliefs toward nine behaviors of varying degrees of ethicality. These survey items were adapted from a questionnaire used by Pratt and McLaughlin (1989). The second part of the questionnaire used Rotter's (1966) Locus of Control questionnaire to determine the students' LOC score for the Internal/External designation for the analysis. The last part of the questionnaire requested demographic information, which is contained in Table 1.

The first part of the survey asked the students to indicate their beliefs toward nine questionable behaviors. Using a Likert scale (where 1 = "very unethical," and 5 = "not at all unethical") students were asked to indicate how unethical they believed each of the nine behaviors to be. The focus was the ethical orientation of the respondents toward the academic-environment behaviors and actions.

Based on the assumptions of LOC theory, an Internal LOC individual is more likely to accept responsibility for his or her actions. The acceptance of responsibility for actions and the expected consequences or outcomes of those actions suggests that those with an internal LOC will respond more ethically because of their belief in the behavior- 
outcome link. By contrast, an External LOC individual is less likely to accept responsibility for the consequences of unethical behaviors, since Externals do not believe in the connection between their actions and the resulting consequences. Without the assumed link between actions and outcome expectancies, Externals are less likely to respond as ethically. Rotter's (1966) LOC instrument is used in the current research to designate student respondents as either Internal or External. The instrument is a 29-item survey developed to sample beliefs across various situations. As such, it is considered to be a "generalized expectancy" measure. The LOC instrument is designed to award a point every time that an external answer is recorded by the subject. Since six of the LOC items are "fillers" and not counted in the scoring, the students' scores can range from zero to 23. Those students scoring less than or equal to 10 on the LOC instrument were designated as Internals. Those scoring greater than or equal to 11 were designated as Externals for the analysis.

The SAS t-test procedure was used to analyze the differences in the students' responses to the items on the questionnaire. The five-point Likert scale mean responses for each survey item were the dependent variable, and the LOC Internal/External designation was the independent variable in the analyses. The Appendix gives the short form of the 9 behaviors surveyed by the questionnaire. All of the behaviors indicated significant differences on the LOC distinction.

Table 3 provides information for the highly significant and consistent results. On all of the survey items, the Internals responded with the greater ethical sensitivity. This offers considerable support for the global nature of LOC as a moderator of ethical beliefs and decisions, as predicted by the research hypothesis. Generally speaking, individuals who believe that they have some responsibility for the outcomes of their own behaviors responded with greater ethical sensitivity. If one blindly accepts attempts at influence by others, that is equivalent to assigning control to others. These results support the belief that Internals are generally less susceptible to negative influence by others. These results further support the results of the Internal/External LOC distinction and the link to ethical beliefs.

\begin{tabular}{|c|c|c|c|c|}
\hline \multicolumn{5}{|c|}{ Table 3 - t-Tests for LOC Response Results $(n=2420)$} \\
\hline Item No. & \multicolumn{2}{|c|}{ Statistics } & \multicolumn{2}{|c|}{ Response Means* } \\
\hline & t-statistic & p-value & Internal** & External** \\
\hline 1 & 4.80 & $<.0001$ & 1.63 & 1.82 \\
\hline 2 & 2.69 & .0071 & 2.93 & 3.08 \\
\hline 3 & 6.45 & $<.0001$ & 1.78 & 2.07 \\
\hline 4 & 4.59 & $<.0001$ & 2.46 & 2.70 \\
\hline 5 & 4.16 & $<.0001$ & 1.59 & 1.77 \\
\hline 6 & 3.49 & .0005 & 1.60 & 1.74 \\
\hline 7 & 4.26 & $<.0001$ & 1.50 & 1.66 \\
\hline 8 & 5.30 & $<.0001$ & 1.61 & 1.81 \\
\hline 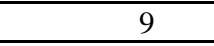 & 7.36 & $<.0001$ & 2.57 & 2.90 \\
\hline
\end{tabular}

\section{DISCUSSION}

This study examines differences in academic ethical responses of university students based on the locus of control (LOC) personality variable. Earlier analysis using US university students have indicated some differences in the LOC variable. This research confirms the relationship between LOC and ethical decisions by focusing on students from eight countries across distinctly different cultures. The survey used in this study presented students with items that would be familiar to them in an academic environment.

As expected, the results indicate strong support for the link between ethical sensitivity and LOC in a multicountry study. In examining the students' individual ethical orientation, all nine survey items indicated significant ( $\mathrm{p} \leq$ .01 ) on the LOC variable. On all 9, the internal LOC students supplied the more ethically sensitive responses. This 
result underscores the importance of understanding the link between LOC and ethically sensitive decisions in a variety of cultures. Overall, the results offer considerable support for the global nature of response differences associated with a LOC variable. However, the LOC/ethicality link has not been studied in all cultures or countries. Additional research investigating these variables across other international combinations is needed to add to a more complete understanding of the way LOC affects ethical decision making.

\begin{tabular}{|l|l|}
\hline \multicolumn{2}{|c|}{ APPENDIX - Short Form of Behaviors Surveyed } \\
\hline No. & Behaviors \\
\hline 1 & Obtaining answers from someone during an exam \\
2 & Discussing exam questions with students from earlier sections \\
3 & Giving answers to someone during an exam \\
4 & Giving exam questions to students in later sections \\
5 & Using an exam stolen by someone else \\
6 & Buying a term paper \\
7 & Copying answers off another's exam \\
8 & Arranging with other students to give/receive answers \\
9 & Working in groups when instructed to work independently \\
\hline
\end{tabular}

\section{REFERENCES}

1. Ameen, E. C., Guffey, D. M., \& McMillan, J. J. (1996). Gender differences in determining the ethical sensitivity of future accounting professionals. Journal of Business Ethics, 15, 591-597.

2. Armstrong, R. W. (1996). The relationship between culture and perception of ethical problems in international marketing. Journal of Business Ethics, 15, 1199-1208.

3. Bass, K., Barnett, T., \& Brown, G. (1999). Individual differences variables, ethical judgments, and ethical behavior. Journal of Business Ethics, 9 (2), 183-205.

4. Brody, R. J., Coulter, J. M., \& Milhalck, P. H. (1998). Whistle-blowing: A cross-cultural comparison of ethical perceptions in U.S. and Japanese accounting students. American Business Review, 16(2), 14-21.

5. Brownell, P. (1982). A field study examination of budgetary participating and Locus of Control. The Accounting Review, 56, 766-777.

6. Brownell, P. (1981). Participating in budgeting, Locus of Control, and organizational effectiveness. The Accounting Review, 56, 844-860.

7. Eynon, G., Hill, N. T., Stevens, K. T., \& Clarke, P. (1996). An international comparison of ethical reasoning abilities: Accounting students from Ireland and the United States. Journal of Accounting Education, 14(4), 477-492.

8. Geurin, V. T., \& Kohut, G. F. (1989). The relationship of Locus of Control and participative decision making among managers and business students. Mid-Atlantic Journal of Business, 25, 57-66.

9. Goodwin, J. \& Goodwin, D. (1999). Ethical judgments across culture: A comparison between business students from Malaysia and New Zealand. Journal of Business Ethics, 18(3), 267-281.

10. Hegarty, W. H., \& Sims, H. P. (1979). Organizational philosophy, policies, and objectives related to unethical decision behavior: A laboratory experiment. Journal of Applied Psychology, 64, 331-338.

11. Hegarty, W. H., \& Sims, H. P. (1978). Some determinants of unethical decision behavior: An experiment. Journal of Applied Psychology, 63, 451-457.

12. Jones, G. E. \& Kavanaugh, M. J. (1996). An experimental examination of the effect of individual and situational factors on ethical behavioral intentions in the workplace. Journal of Business Ethics, 15, 511-523.

13. Licata, M. P., Strawser, R. H., \& Welker, R. B. (1966). A note on participation in budgeting and Locus of Control. The Accounting Review, 61, 112-117.

14. Lysonski, S. \& Gaidis, W. (1991). A cross-cultural comparison of the ethics of business students. Journal of Business Ethics, 10, 141-150.

15. McCuddy, M. K., \& Peery, B. L. (1996). Selected individual differences and collegians' ethical beliefs. Journal of Business Ethics, 15, 261-272. 
16. Newstrom, J. W. \& Ruch, W. A. (1976). The ethics of business students: Preparation for a career. AACSB Bulletin, 12 (April), 21-29.

17. Nyaw, M. \& Ng, I. (1994). A comparative analysis of ethical beliefs: A four country study. Journal of Business Ethics, 13 (7), 543-555.

18. Pratt, C. B. \& McLaughlin, G. W. (1989). An analysis of predictors of college students' ethical inclinations. Research in Higher Education, 30, 195-219.

19. Rogers, V. \& Smith, A. (2001). Ethics, moral development, and accountants-in-training. Teaching Business Ethics, 5, 1-20.

20. Rotter, J. B. (1966). Generalized expectancies for internal versus external control of reinforcement. Psychological Monographs, 80 (Whole No. 609).

21. Smith, A., Coates, J. D., \& Deis, D. R. (1998/99). Are ethical responses linked to Locus of Control? Teaching Business Ethics, 2(3), 249-260.

22. Smith, A., Hume, E. C., Davis, A. B., \& Zimmermann, R. (2004). The Universal Relevance of Locus of Control in Ethical Decision Making: A Multi-Country Examination. Journal of Legal, Ethical and Regulatory Issues, 7 (1\&2), 15

23. Spector, P. E., \& Michaels, C. E. (1986). Personality and employee withdrawal: Effects of Locus of Control on turnover. Psychological Reports, 59, 63-66.

24. Stevenson, T. H. \& Bodkin, C. D. (1998). A cross-national comparison of university students' perceptions regarding the ethics and acceptability of sales practices. Journal of Business Ethics, 17(1), 45-55.

25. Storms, P. L. \& Spector, P. E. (1987). Relationships of organizational frustration with reported behavioral reactions: The moderation effect of Locus of Control. Journal of Occupational Psychology, 60, 227-234.

26. Terpstra, E. E., Ryes, G. C., \& Boker, D. W. (1991). Predictors of ethical decisions regarding insider trading. Journal of Business Ethics, 10, 699-710.

27. Trevino, L. K. \& Youngblood, S. A. (1990). Bad apples in bad barrels: A causal analysis of ethical decisionmaking behavior. Journal of Applied Psychology, 75, 378-385.

28. Ueno, S. and Wu, F. H. (1993). The comparative influence of culture on budget control practices in the United States and Japan. The International Journal of Accounting, 28, 17-39.

29. Whipple, T. W. \& Swords, D. F. (1992). Business ethics judgments: A cross cultural comparison. Journal of Business Ethics, 11, 671-678.

30. White, L. P. \& Rhodeback, M. J. (1992). Ethical dilemmas in organizational development: A cross-culture analysis. Journal of Business Ethics, 11, 663-670.

31. Yamamura, J. H., Frakes, A. H., Sanders, D. L., and Ahn, S. K. (1996). A comparison of Japanese and U.S. auditor decision-making behavior. The International Journal of Accounting, 31, 347-363. 